\title{
Performance of large-scale irrigation projects in sub- Saharan Africa
}

DOI:

10.1038/s41893-020-00670-7

\section{Document Version}

Accepted author manuscript

Link to publication record in Manchester Research Explorer

\section{Citation for published version (APA):}

Higginbottom, T. P., Adhikari, R., Dimova, R., Redicker, S., \& Foster, T. (2021). Performance of large-scale irrigation projects in sub-Saharan Africa. Nature Sustainability. https://doi.org/10.1038/s41893-020-00670-7

\section{Published in:}

Nature Sustainability

\section{Citing this paper}

Please note that where the full-text provided on Manchester Research Explorer is the Author Accepted Manuscript or Proof version this may differ from the final Published version. If citing, it is advised that you check and use the publisher's definitive version.

\section{General rights}

Copyright and moral rights for the publications made accessible in the Research Explorer are retained by the authors and/or other copyright owners and it is a condition of accessing publications that users recognise and abide by the legal requirements associated with these rights.

\section{Takedown policy}

If you believe that this document breaches copyright please refer to the University of Manchester's Takedown Procedures [http://man.ac.uk/04Y6Bo] or contact uml.scholarlycommunications@manchester.ac.uk providing relevant details, so we can investigate your claim.

\section{OPEN ACCESS}


1. Performance of large-scale irrigation projects in Sub-Saharan Africa

${ }_{3}$ Thomas P Higginbottom ${ }^{* 1}$, Roshan Adhikari², Ralitza Dimova ${ }^{2}$, Sarah ${ }_{4}^{4} \quad$ Redicker $^{2}$, and Timothy Foster ${ }^{1}$

${ }_{5}^{1}$ Department of Mechanical, Aerospace, and Civil Engineering, University

6

7

\section{Abstract}

of Manchester, Manchester, UK

${ }^{2}$ Global Development Institute, School of Environment, Education and Development, University of Manchester, Manchester, UK

January 22, 2021

After a thirty-year hiatus, large-scale irrigation projects have returned to the development agenda in sub-Saharan Africa (SSA). Yet, the magnitude and drivers of past schemes performance remains poorly understood. We quantify the performance of 79 irrigation schemes from across SSA, measured as the proportion of proposed irrigated area delivered, by comparing planning documents with estimates of current scheme size from satellite-derived land cover maps. We find overwhelming evidence that investments have failed to deliver promised benefits; with schemes supporting a median $16 \%$ of proposed area, only $20(25 \%)$ delivering $>80 \%$, and $16(20 \%)$ completely inactive. Performance has not improved over six decades, and we find limited relationships with commonly stated causes of failure such as scheme size and climate.

thomas.higginbottom@manchester.ac.uk 
We attribute these findings to political and management frameworks underpinning irrigation development in SSA. Firstly, an emphasis on national food security promotes low value crops, reducing economic viability. Secondly, proposals are unrealistically large, driven by optimism bias and political incentives. Finally, centralised bureaucracies lack the technical expertise, local knowledge, and financial resources to ensure long-term maintenance. Our findings highlight the need for greater learning from past investments outcomes if improvements in agricultural productivity and water security across SSA are to be realised.

\section{Introduction}

Water scarcity is a major driver of crop yield gaps in smallholder farming systems across Asia and Africa outside of the tropics [30, 42]. Consequently, the development and expansion of irrigation infrastructure has long been emphasised as a solution to intensify agricultural production, support rural economic development, and enhance resilience to climate variability and change $[11,16]$.

In sub-Saharan Africa (SSA), state-supported irrigation development has historically occurred through construction of dams and associated surface water canal irrigation infrastructure [5]. These projects - ranging in size from 400 to over 100,000 ha — were initiated first by colonial administrations in the early $20^{\text {th }}$ century $[11,16,21]$, with development accelerating in the $1960 \mathrm{~s}$ due to support from multilateral donors such as the World Bank and African Development Bank [12]. Investments have been considerable, irrigation projects in SSA are estimated to cost up to $\$ 20,000$ per hectare [14].

Despite such considerable investments, the benefits of irrigation scheme remain highly disputed. Site-specific case studies suggest many developments have failed to achieve intended goals of improving agricultural productivity and rural livelihoods $[57,48,5]$, with evidence of significant and increasing yield gaps due to scheme deterioration post-construction [13, 14]. Diverse explanations have been put forward to explain these failures [7, 41], including changes in local hydro-climatology post-construction [14, 5], inadequate scheme maintenance [49], and constraints on the productivity of irrigated crops imposed by land tenure and other factors $[48,14,20]$. However, to date, no study has attempted to quantify scheme performance or causes of failure at regional scales beyond these individual site-specific case studies. 
Following a near 30-year hiatus in public irrigation development in SSA [58, 54], countries across the region are now entering a renewed era of investment in large-scale irrigation infrastructure. The Dakar Declaration, signed in 2013 by six Sahelian nations and multilateral donors, committed to developing 600,000 ha of irrigated land by 2020 , at a cost of $\$ 7$ billion [32]. Similarly, since 2004 the US Millennium Challenge Corporation has invested nearly $\$ 700$ million for agricultural development, including $\$ 257,199,000$ for large-scale developments in Niger, and $\$ 247,700,000$ for the Alatona Irrigation Scheme expansion in Mali [40]. In the context of these developments, improved empirical evidence about the performance of past irrigation investments would provide valuable guidance to support planning of future large-scale irrigation infrastructure in SSA.

Here, we provide a comprehensive data-driven, regional-scale assessment of irrigation scheme performance for sub-Saharan Africa. Our results show significant and persistent underperformance of irrigation investments across SSA, persisting over a period of over six decades. We discuss potential underlying drivers of the observed tendency to over-promise and under-deliver in scheme planning. Finally we demonstrate significant gaps in data required to adequately quantify causal determinants of infrastructure project outcomes that, if not addressed, will inhibit capacity to sustainably and cost-effectively intensify irrigation water use across the region to support improvements in food security, reduce poverty, and stimulate economic growth and development.

\section{Results}

Information about proposed irrigated areas were identified for 79 schemes across 24 nations (Figure 1.a) in SSA, predominantly from World Bank and African Development Bank document archives (full list in source data). Summary statistics of proposals and outcomes for African Union regions are given in Table 1. There was pronounced national and regional variation in the number of schemes identified; Nigeria and West Africa were the most represented nation and region, with 14 and 44 sites, respectively (Figure 1.b). This disparity was expected, as West Africa has been targeted for more state-backed irrigation development relative to southern and eastern regions where small-scale private estates dominate [5]. For each scheme, we generated a satellite-derived irrigation map quantifying the area of irrigation currently supported by the 
project as described in Section 4.

Irrigation scheme performance is influenced by complex interactions between economic, environmental, climatic, and management factors. To evaluate the contribution of different drivers, we assessed the relationship between irrigation scheme outcome and eight variables suggested by previous research (see Section 4) $[45,5,18]$. To allow for potential non-linearity in these relationships, we used generalized additive models (GAMs), which are capable of describing non-linear and non-monotonic terms (Section 4). Each variable was fit in a separate model, incorporating country as a random effect. We fit two groups of models, representing scheme outcomes in different ways; Model 1 uses a quasibinomial functional form to identify drivers of different levels of scheme performance on a continuous scale, ranging from $0 \%$ (full failure) to 100\% (full delivery). In contrast, Model 2 represents irrigation delivery as a binary variable, providing a mechanism to identify determinants of failed (i.e. zero delivery) vs operational (i.e. non-zero delivery) schemes. Scatter plots of the selected variables are shown in Figure 3, and modelled smoothed curves for the GAMs are given in the SI. Statistical summaries for all model terms are given in Table 2. Further details of underlying model differences and choices are given in Section 4.

Our analysis revealed three main results. Firstly, irrigation schemes have consistently failed to deliver their proposed irrigated agricultural land areas (Figure 2). Only 20 projects achieved $80 \%$ or more of their proposed area, with median (mean, mean excluding zeros) rates of delivery of $18 \%(41 \%, 52 \%)$ across our sample of 79 projects in SSA (Figure 2). Second, our data show that there is no evidence that rates of scheme performance having improved over time, despite our analysis considering schemes constructed over a more than six decade period between 1948 and 2008. Finally, across both sets of statistical models, we find only limited and relatively weak statistical relationships between irrigation scheme performance and commonly reported causes of project failures such as scheme size and climate variability. The one exception to this is government effectiveness, for which low values (indicative of poor government effectiveness) are statistically significantly associated $(P=0.03)$ with higher likelihood of scheme failure in the binomial form GAM. We discuss the underlying drivers of these findings and their implications for irrigation development planning and policy in SSA in the following section. 

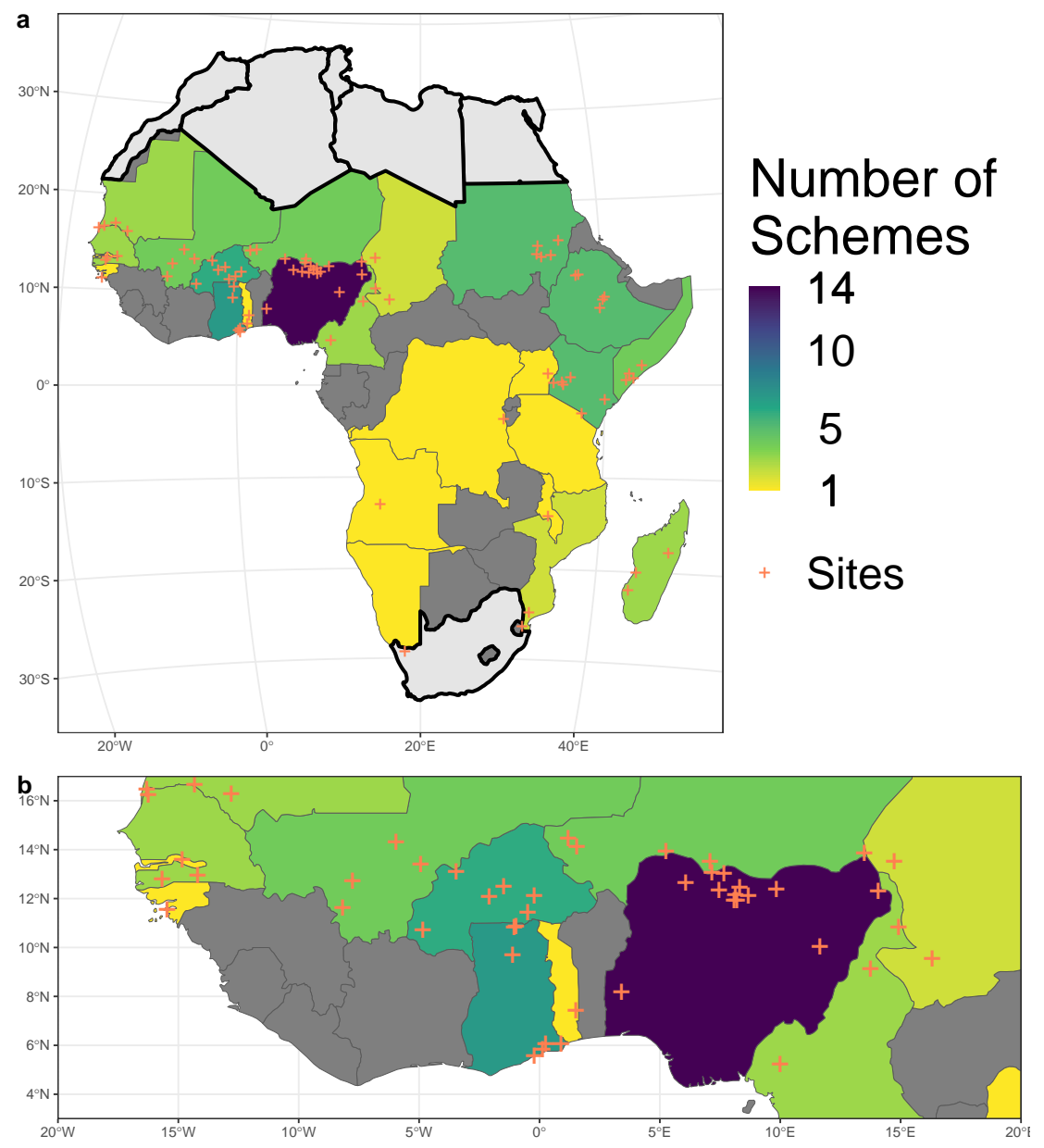

Figure 1: a) Geographic distribution of the 79 irrigation schemes represented in our analysis, with number of sites per country. Light grey nations were not included in the study.

b) West Africa zoom-in map

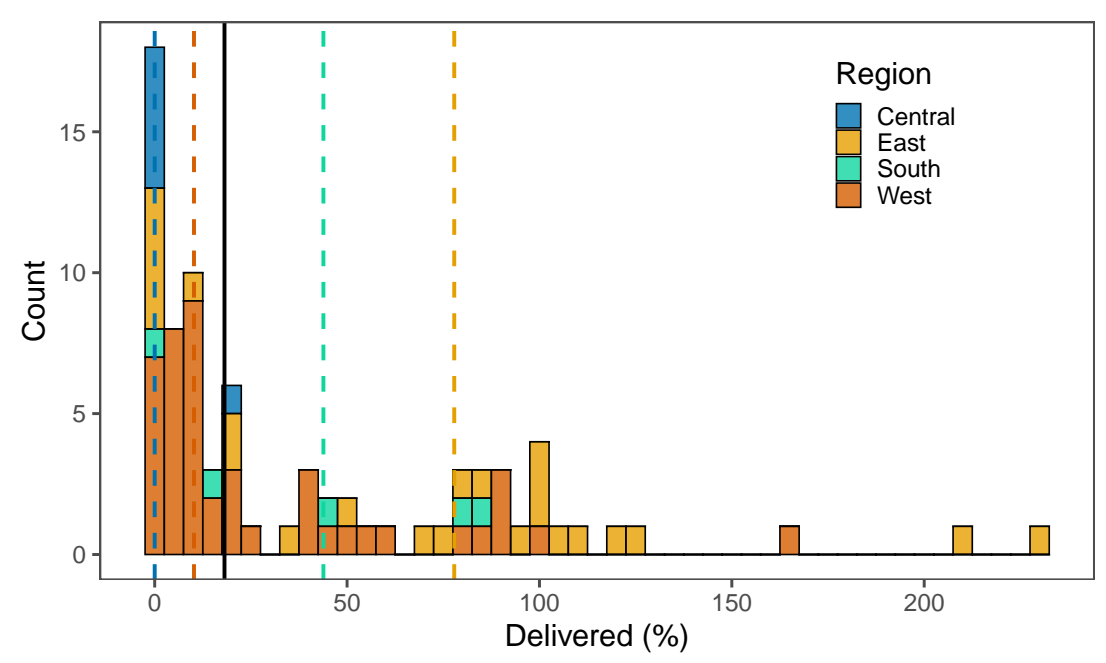

Figure 2: Histogram of the percentage of irrigation delivered, colour correspond to African Union regions. Vertical lines are group median values, the black line is median for all samples 

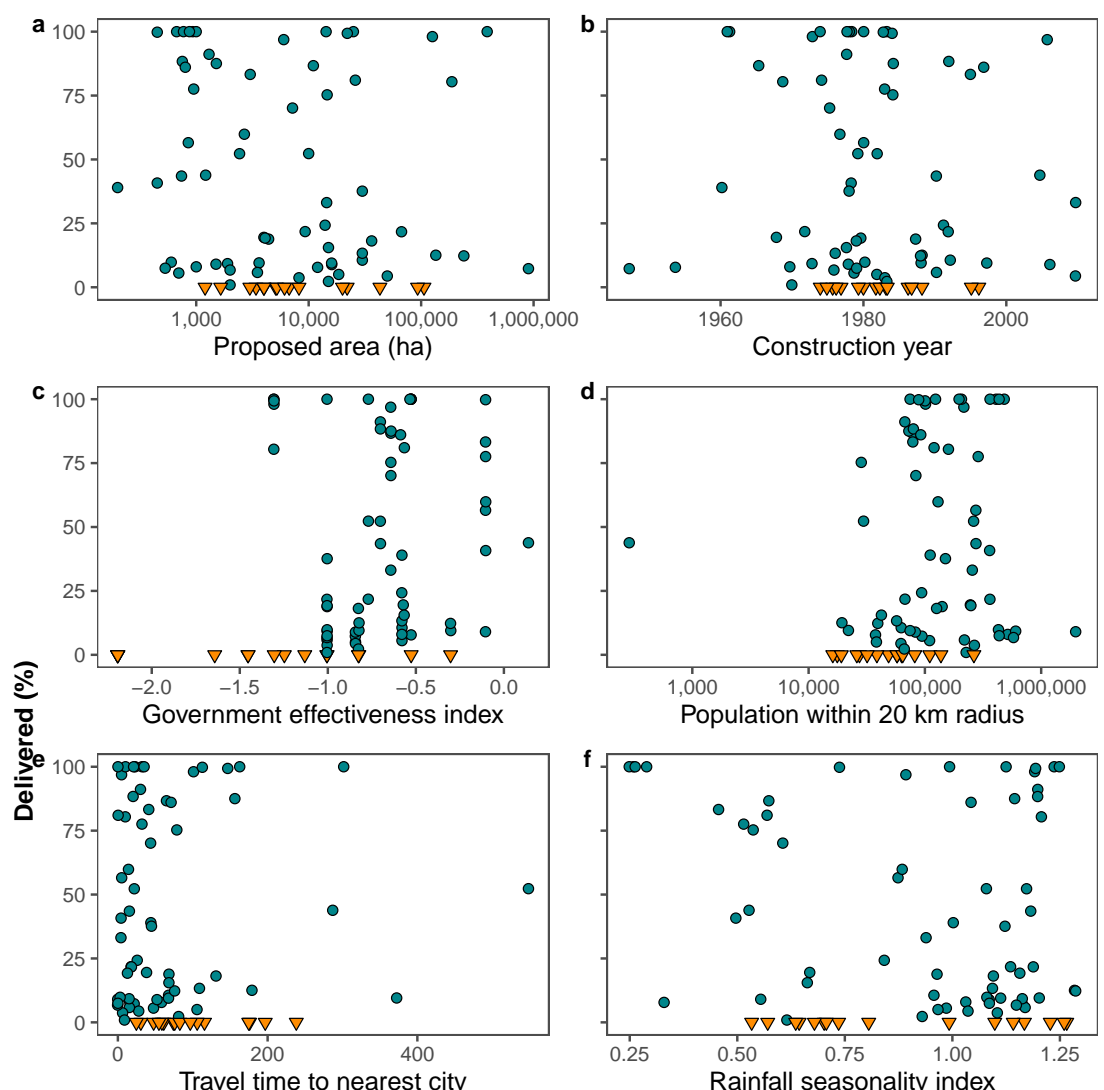

Population within $20 \mathrm{~km}$ radius
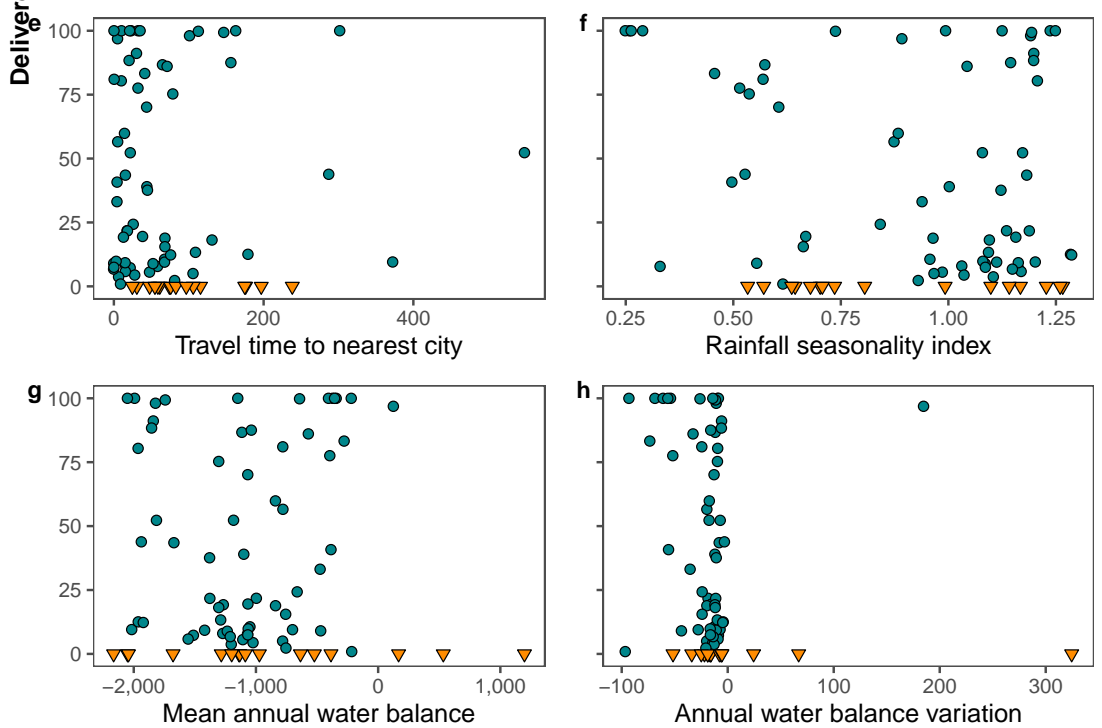

Figure 3: Relationships between delivered irrigated percentage and potential explanatory variables. Delivery percentage were capped at 100\%, orange triangles are completely inactive schemes

\begin{tabular}{cccccc}
\hline \hline & & Proposal & & Delivered & \\
Region & $\mathrm{n}$ & Mean (ha) & Median (ha) & Mean (\%) & Median (\%) \\
\hline Central & 6 & 10,933 & 5,050 & 3 & 0 \\
East & 24 & 37,543 & 9,650 & 73 & 78 \\
South & 5 & 27,202 & 15,000 & 45 & 44 \\
West & 44 & 40,337 & 3,210 & 29 & 10 \\
\hline
\end{tabular}

Table 1: Number and summary statistics of the scheme proposals identified, for African Union geographic regions. Mauritania was reclassified from North to West, as no other North African nation was included in our study. 


\begin{tabular}{lllllllll}
\hline & \multicolumn{3}{l}{ Model 1: Quasibinomial } & \multicolumn{5}{c}{ Model 2: Binomial } \\
& edf & Ref df & F-value & P & edf & Ref df & F-value & P \\
\hline Log Proposal size & 2.49 & 3.12 & 2.44 & 0.08 & 2.33 & 2.88 & 2.29 & 0.55 \\
Year & 1.00 & 1.00 & 0.01 & 0.92 & 2.32 & 2.95 & 1.37 & 0.70 \\
GEI & 1.00 & 1.00 & 3.25 & 0.08 & 1.45 & 1.69 & 9.21 & $0.03^{*}$ \\
Log Population & 4.13 & 4.92 & 2.14 & 0.08 & 2.40 & 2.90 & 5.90 & 0.11 \\
Travel & 1.00 & 1.00 & 0.00 & 0.99 & 2.74 & 3.34 & 4.82 & 0.23 \\
Seasonality index & 3.85 & 4.69 & 1.68 & 0.16 & 3.38 & 4.05 & 4.09 & 0.40 \\
Water Balance (mean) & 1.00 & 1.00 & 0.87 & 0.36 & 2.85 & 3.48 & 4.19 & 0.32 \\
Water Balance (CV) & 2.57 & 3.02 & 1.27 & 0.29 & 1.00 & 1.00 & 1.79 & 0.18 \\
\hline
\end{tabular}

Table 2: Statistical summaries of GAM models used to assess drivers of irrigation scheme performance. Each model included a random effect for nation (not shown), full model outputs are given in the SI.

\section{Discussion}

Our data provide robust evidence that formal irrigation developments in SSA are routinely smaller in size than proposed and also have a non-trivial likelihood of completely stopping operations. We find no evidence of improvement in project performance over a six decade study period, and, critically, highlight that the empirical causes of these failures remain unclear at regional scale. Conceptually, we argue the persistent underperformance of irrigation schemes in SSA reflects fundamental issues throughout both planning and implementation, which mirror challenges faced within wider infrastructure development and governance. In the following sections, we discuss key insights and explanations regarding the systematic failure of past irrigation developments in SSA, contextualising our results within an infrastructure development and governance framework to discuss knowledge gaps and solutions for improving irrigation planning in the region.

\section{Over-optimistic planning is not solely due to poor data}

Irrigation schemes are textbook examples of infrastructure mega-projects: large-scale, complex, and contextually expensive undertakings. Mega-projects are often characterised by poor projections, with over-promising of benefits and under-estimation of costs in the planning process [27]. Indeed, the magnitude of scheme underperformance identified here is consistent with findings in other sectors, including: hydropower dams, transport schemes, military contracts, and development projects $[9,33,24,27]$. Flyvbjerg et al [26] propose that inaccurate projections originate 
from three sources: i) technical, due to unforeseen circumstances or poor data; ii) psychological, when planners are unrealistically optimistic; and iii) political-economic, where costs and returns are deliberately adjusted to achieve project approval. We discuss each of these sources within the context of irrigation scheme performance outcomes in SSA as identified in our analysis.

All agricultural planning in SSA is constrained by limited data and understanding, on climatic, agronomic and pedological factors. These limitations point to a possible technical underpinning for overoptimistic expectations about irrigation scheme delivery, compounded by idiosyncratic challenges afflicting schemes. However, an ingrained focus on agriculture and irrigation as a purely technical endeavours is exemplary of two development frameworks that plant seeds for future problems. First, governments act according to their perception of the world, based on official data and ideological underpinnings $[47,36]$. Smallholder farmers are poorly represented in agricultural statistics and often viewed as unproductive by officials, their local knowledge and adaptations will therefore often be ignored [23]. Secondly, agriculture is a socio-economic sector, embedded in local social structures, focusing on technical solutions and excluding socio-economic (rendering technical) will disrupt these structures, incurring negative impacts on agricultural productivity and resilience [37]

There are clear challenges for irrigation development caused by the absence of data in SSA. Yet our data show a non-random pattern, with a clear bias towards over-prediction and only 20 project achieving $80 \%$ of their target area. This skew combined with an absence of any trend in improvement over time suggests technical causes alone can not explain planner's optimism. Indeed, World Bank reports show a patterns of issues reoccurring over time [56, 55], with little evidence here that planners are learning from experience or improving decision-making in response to improvements in data availability. If improved data, previous experiences, and institutional review processes do not improve outcomes, it is unlikely that the core problem is of technical expertise. Accordingly, psychological and political factors may be relevant to explaining the observed over prediction.

\section{Full attainment of proposals was unlikely for many schemes}

Positioning over optimistic planning as a response to political pressures is consistent with the history of how irrigation schemes have been envisaged and proposed in SSA. In post-colonial Africa, nationalist idealism combined with the World Bank's poverty-reduction mandate pro- 
duced a boom for irrigation development [41], with water-based infrastructure often a symbolic investment representing modernity and technological progress [47]. While data to support planning has improved somewhat over recent decades as noted in the previous section, many of the original motivations for and underpinnings of scheme development remain the same - a factor we suggest below may go some way to explaining the lack of improvement in scheme performance over time.

Irrigation development in SSA, in particular the construction of large government-managed schemes, is intended to secure national food security $[14,4]$. This focus is reflected in the prioritisation of staple grain and rice production in many schemes, crops which are low value and typically require large - often unachievable - harvests to generate significant economic returns on production [14]. Critically, national food security goals are somewhat misaligned with the common assumption, in particular from donors and finances, of irrigation projects as cost-effective and economically self-sustaining. We argue that this disconnect between goals of government and project finances creates significant incentives for planners to over-promise and under-deliver on long-term scheme outcomes, as if true costs and benefits of projects were accounted for at the planning stage then many would not be viewed as economically viable or sustainable over the project lifespan. This paradox is not unique to irrigation schemes, and occurs on many mega-projects [26].

A consequence of planners over-promising and under-delivering is that the maintenance and upkeep of infrastructure suffers, in particular once core project funding ends shortly after construction [17]. Resulting infrastructure failures have cascading effects on scheme functioning, consistent with wider examples on the effects of failure in other complex fragile systems $[10,12]$. The result is a 'build-neglect-rebuild' cycle, with schemes allowed to deteriorate on the assumption of future funding for rehabilitation. Furthermore, cost overruns can prevent the implementation of supplementary agricultural facilities which are the final components, further reducing scheme viability. For example, failure to construct planned tomato processing plants contributed to the economic failure of the Bakolori scheme in Nigeria (currently supporting $37 \%$ of a planned 30,000 ha), while breakdown of adjacent rice mills contributed to the eventual complete failure of the Sategui-Deressia scheme in Chad $[2,55]$.

Arguably, many challenges to scheme sustainability were predictable from the outset, but were ignored or inadequately factored in to planning and design. While Hirschman [8] posited 
that ignorance in planning can be beneficial - allowing the initiation of projects that would be rejected, with a 'hidden hand' fostering creative problem solving - there is little evidence of such outcomes occurring in irrigation scheme developments. Farmers do adapt to failing irrigation schemes, notably using diesel groundwater pumps or independently building informal irrigation developments using scheme infrastructure $[2,4,22]$. However, such initiatives rarely compensate for the large costs of scheme development. We attribute the lack of clear evidence for a 'hidden hand' phenomena in our sample to two factors. First, irrigation schemes reduce agricultural adaptability by appropriating water and land, and by regulating the sale or renting of plots $[14,15]$. Secondly, social aspects of development are often the most intractable, with technically minded planners less focussed on issues such as gender dynamics or resettlement programs associated with projects $[20,37]$.

\section{No clear regional-scale drivers of scheme performance}

Our findings illustrate the scale and persistence of underperformance by irrigation schemes in SSA. While we have postulated some likely underpinnings of these outcomes, an important finding from our analysis is the limited relationship between scheme performance and factors commonly attributed as causal agents.

Blanc and Strobl [18] found that large dams were negatively associated with cropland productivity in South African river basins, but this effect reversed when smaller dams were also present, suggesting that smaller irrigation infrastructure developments may have more positive impacts on agricultural production outcomes than larger schemes. This is comparable with wider literature assessing relationships between infrastructure scale and performance [46]. However, we found marginally insignificant relationships $(P=0.08)$ between project proposal size and either delivery rate or likelihood of scheme failure.

Similarly, climate variability has been proposed as a cause for numerous scheme failures, yet we find no relationship at regional scale between any metric of climate conditions or variability. A potential explanation is that climate is simply a contributing factor to the failure of schemes that were already deteriorating and poorly planned from the outset [4]. For example, the Nigerian South Chad Irrigation Project achieved $3 \%$ of the planned area, before failing completely as water availability declined. Drought undeniably foreclosed the possibility of irrigation, but the scheme had experienced continual management and maintenance problems since it's delayed opening, 
partly due to lower oil prices reducing Nigeria's income [4, 15]. Furthermore, the decline in water availability should not have surprised planners, colonial authorities had documented both multi-year droughts in the early $20^{\text {th }}$ century and variations in the area of Lake Chad by up-to $50 \%$ [34]. Indeed, the World Bank acknowledged that many schemes in the region may not have succeeded independent of changing hydrological conditions post-construction [56], suggesting that, consistent with our findings, climate alone is insufficient to explain instances of scheme failure.

The only significant factor identified by our analysis was government effectiveness, with lower values a significant predictor of scheme failure $(P=0.03))$. Governance is a one-dimensional, simplistic measure that may have varying localised manifestations. However, GEI index correlates with general development measures, such as engineering and economic capacity; prerequisites for the operation and maintenance of profitable irrigation schemes [45]. The state has an unavoidable role in irrigation development, by possessing ultimate control over land and water [16]. Following construction, the state may directly undertake operations or extract income from rents. In either role, state capacity to provide support is crucial to scheme success, and the intrusion of inefficient national bureaucracies can produce negative outcomes that compound challenges posed by over-optimistic scheme planning and design [3]. Indeed, in states with very low governance scores (e.g Somalia and Chad), almost all schemes in our sample were nonfunctional. In contrast, it is notable that the two largest schemes in our sample - the Office du Niger in Mali and Gezira in Sudan - transitioned away from declining yields by undertaking liberalising reforms, focused on less state control and more autonomous operation by farmers $[11,16]$. For both nations, these reforms occurred during periods of relative good governance: mid-2000s in Sudan and following the 1991 establishment of democracy in Mali. Overall, the importance of governance is consistent with wider evidence on success of development initiatives. Post-conflict settings increase the likelihood that World Bank infrastructure projects fail [24], yet irrigation projects continue to be proposed as development catalysts in extremely fragile states such as Afghanistan, Somalia, and The Democratic Republic of Congo [6, 29, 39]

\section{What is needed to improve future irrigation developments?}

Our findings show irrigation schemes are consistently smaller in size than planned and have non-trivial rates of stopping operations after construction, with no noted improvements over 
60 years of development. Overall our findings are consistent with evidence on outcomes from wider infrastructure mega-projects, which are often associated with large cost overruns and poor delivery compared to initial plans $[25,26]$. Yet irrigation schemes and dams are more than their component structures, and the consequences of failure are more severe than expense for the state. Constructing irrigation schemes and dams transforms river basins, irreversibly altering the natural environment [5]. When schemes are smaller than planned either less farmers will receive land or the plots will be smaller than promised [14]. Both of these outcomes have far reaching negative implications for poverty alleviation and food security, in particular where new infrastructure disrupts pre-existing livelihood systems $[2,20]$.

Water infrastructure development, including large dams, is accelerating across SSA, with irrigation often stated as a justification. Many proposed projects continue to promise huge irrigation potential; planners of the Pwalugu dam in Ghana claim it will deliver 20,000 ha, whilst the Kandadji dam in Nigeria promises 122,000 ha. The cost of formal large-scale irrigation is considerable, regularly in excess of $\$ 20,000$ per ha. When considering more realistic estimates of likely performance, we argue that the true economic viability of both past and future projects is significantly lower than estimated. The need for irrigation infrastructure nevertheless remains, and will likely increase in the coming decades with intensifying and more frequent hydro-climatic extremes due to climate change. Reforming scheme design and management for example through alternative cropping mixes, or greater involvement of farmers - could help improve the cost-effectiveness and sustainability of such developments. Alongside this, planners could consider alternative mechanisms to improve water security of farmers in SSA, including less formalised or technocratic alternatives, such as farmer-led irrigation, that may provide complementary low-cost solutions for improving food production, alleviating poverty, and stimulating rural entrepreneurship and innovation [19, 54].

Central to better policies will be improved data and understanding on the performance of past irrigation investments. Our study has highlighted the challenges of attributing causal effects to scheme performance outcomes. Our dataset represents a unique collection of planned outcomes for irrigation schemes in SSA, supported by Earth observation analysis that to date has been underutilised in development project impact monitoring. Yet, our sample remains biased towards assessment of irrigated area - neglecting factors such as yields or cropping intensity and to projects with accessible documentation (e.g., World Bank funded schemes). In addition, 
there is still an absence of information about contextual variables, such as cropping patterns, scheme governance, and rehabilitation programs, for schemes in SSA, which precludes more complex quantitative analysis of climatic, economic and socio-political factors governing scheme performance. Gaps in evidence remain despite decades of critical research on irrigation in SSA, highlighting the need for planners and donors to engage in more systematic, transparent and publicly documented appraisal and monitoring of irrigation development programs. This would help promote intensification and expansion of irrigation development that is cost-effective, sustainable and equitable in its outcomes.

\section{Data and Methods}

The following sections describe the datasets and methods used to quantify the proportion of proposed irrigation successfully delivered for the 79 schemes across SSA shown in Figure 1.

\section{Proposed Irrigation Areas}

We reviewed published studies and official documents to identify records for proposed irrigated areas for schemes across SSA. To be included in our dataset, documentation had to: (i) clearly state a proposed or planned irrigated area: not a potential or maximum viable area, and (ii) originate form a reputable source: such as a government department, peer-reviewed publication, or a development funding agency. Sources were obtained from as close to the project construction date to increase reliability of proposal estimates. We used records for schemes constructed between 1945 and 2008; as this period has available documentation, and covers the main period of large-scale irrigation development in SSA, while excluding very recent schemes that may not yet be fully operational. Where schemes were designed to facilitate multiple annual harvests, proposals were checked to ensure the proposed area reflected the annual irrigated scheme area, thus providing consistency with satellite-based estimates of delivered irrigated areas described below.

\section{Delivered Irrigation Areas}

To quantify how much irrigation is currently delivered by a scheme, for each site we created a map of irrigation frequency for 2014 to 2018. First, we defined the boundary of each irrigation scheme 
in our sample. There is no standardised, spatially-explicit data on dam irrigation command area for our study region. Therefore, the command areas for the selected dams were manually digitised. When the proposed irrigation was concentrated in a designated scheme, site maps and aerial imagery were used to delineate boundaries. Where no individual scheme was planned, a proximate boundary was drawn based on proximity to the river or canal network and visual inspection of the Landsat metric composites. Subsequently, we developed binary irrigated - non irrigated land cover maps for each scheme, using a range of Landsat 8 spectral temporal metrics (including both standard deviation and a range of percentiles for each) that have been widely used for land cover mapping $[31,43]$. Metrics were then classified in to a binary land cover map using a Random Forest classifier [44], with training data drawn based on contemporaneous high-resolution imagery in Google Earth and the Landsat metrics. The area of active irrigation was then calculated based on the sum of pixels classified as irrigated in at least 3 out of 5 years from 2014-2018 - chosen to allow for land to undergo fallow rotations without being discounted from our irrigation statistics — that intersect with the command area boundary for each irrigation scheme. The irrigation maps were validated using a stratified samples of 500 points, distributed across all the sites, this returned a overall accuracy of $88 \%$. Our analysis did not distinguish between multiple annual croppings or the season in which irrigation was applied, and all processing was undertaken in the Google Earth Engine cloud environment [28].

\section{Explanatory Variables}

Many factors have been proposed as drivers of failure (or success) in irrigation developments $[45,57]$. To identify which variables contribute to the irrigation scheme performance, we collated a series of 8 potential predictors. These factors cover national and site-specific drivers of scheme performance, in addition to a range of explanatory hydro-climatic metrics. Hydro-climatic factors (6-8 below) were calculated using data from the TerraClimate database [1] for the period 1958-2015, which was selected due to its long historic coverage and high spatial resolution (4 $\mathrm{km}^{2}$ ). Below, we summarise in brief each of the 8 selected variables for the sites studied

1. Construction year the year when construction on the scheme was finished, based on the source documentation

2. Travel time to the nearest city in hours for each site, according to analysis by the Malaria 
Atlas Project, using road networks from Open Street Map and Google Streets incorporating additional travel friction layers. Data was produced for 2015 and provided at a $1 \mathrm{~km}^{2}$ grid cell resolution, for full details see [51]

3. Proposal size the area in hectares of the initial proposal, as per the source documentation

4. Population within a $20 \mathrm{~km}^{2}$ radius of each scheme, based on $1 \mathrm{~km}^{2}$ population maps from $[38]$

5. Government effectiveness for each nation, based on the World Bank's composite measure. This measure reports annually and combines data on six dimensions of government capacity (voice and accountability, political stability and absence of violence, government effectiveness, regulatory quality, rule of law, control of corruption; [35]). To obtain a robust long-term variable, we calculated the median value of the index for each country, for the 1996 - 2017 time period covered by the data.

6. Mean annual water balance for each site, representing total annual precipitation minus total potential evapotranspiration calculated using TerraClimate

7. Water balance variability for each site, representing the co-efficient of variation of the annual water balance calculated using TerraClimate

8. Rainfall seasonality index for each site, summarising the degree of month to month variability in rainfall based on the simple index defined by [50]

\section{Statistical Analysis}

We analysed the magnitude and causes of discrepancy between proposed and delivered irrigation capacity through a series of Generalised Additive Models (GAMs). GAMs are non-parametric models, where the predictor variables can be represented by smoothed non-linear functions [53]. These smooth terms are constructed without prior knowledge of their functional form and are based on splines developed using Restricted maximum likelihood [52].

We developed two alternative sets of models using different distribution families to account for the nature of our response variable (delivered irrigation). These models were: 1) a quasibinomial distribution, with the data rescaled to the 0 -1 range (representing 0-100\%) with values greater 
than 1 capped, this structure prevents the parameter fits exceeding 100\% or dropping below $0 \%$ and captures scheme performance over a continuous range. And, 2) a binomial model with a logit link, for this model we developed a 'failed scheme' binary variable, modelling schemes supporting $0 \%$ of their irrigation target using a logistic function. In all models, the dependent variable was regressed against the each individual variable, with nation added as a random effect to minimise pseudo-replication.

\section{Data availability}

Data and code to produce the figures and statistical analysis is available attached source data. For further queries contact Tom Higginbottom.

\section{Authorship statement}

T.H. and T.F. designed the research. T.H collated the data and performed all computations and analyses. T.H and T.F. wrote the manuscript with input from all authors

\section{Acknowledgement}

This research was funded by the FutureDAMS project (grant code: ES/P011373/1), through the Global Challenges Research Fund from UK Research and Innovation (UKRI)

\section{Ethics declarations-Competing interests}

The authors declare no competing interests.

\section{References}

[1] J. T. Abatzoglou, S. Z. Dobrowski, S. A. Parks, and K. C. Hegewisch. Terraclimate, a highresolution global dataset of monthly climate and climatic water balance from 1958-2015. Scientific data, 5:170191, 2018.

[2] W. M. Adams. The downstream impacts of dam construction: a case study from nigeria. Transactions of the Institute of British Geographers, pages 292-302, 1985. 
[3] W. M. Adams. How beautiful is small? scale, control and success in kenyan irrigation. World development, 18(10):1309-1323, 1990.

[4] W. M. Adams. Large scale irrigation in northern nigeria: performance and ideology. Transactions of the Institute of British Geographers, pages 287-300, 1991.

[5] W. M. Adams. Wasting the Rain: Rivers, People and Planning in Africa. Earthscan, 1992.

[6] R. Ahlers, L. Brandimarte, I. Kleemans, and S. H. Sadat. Ambitious development on fragile foundations: Criticalities of current large dam construction in afghanistan. Geoforum, 54: 49-58, 2014.

[7] M. Alam. Problems and potential of irrigated agriculture in sub-saharan africa. Journal of Irrigation and Drainage Engineering, 117(2):155-172, 1991.

[8] L. Albert. Development projects observed. Brookings, Washington, 1967.

[9] A. Ansar, B. Flyvbjerg, A. Budzier, and D. Lunn. Should we build more large dams? the actual costs of hydropower megaproject development. Energy Policy, 69:43-56, 2014.

[10] A. Ansar, B. Flyvbjerg, A. Budzier, and D. Lunn. Big is fragile. Oxford University Press Oxford, 2017.

[11] D. Aw and G. Diemer. Making a large irrigation scheme work: a case study from Mali. The World Bank, 2005.

[12] O. Awojobi and G. P. Jenkins. Were the hydro dams financed by the world bank from 1976 to 2005 worthwhile? Energy Policy, 86:222-232, 2015.

[13] V. Balasubramanian, M. Sie, R. J. Hijmans, and K. Otsuka. Increasing rice production in sub-saharan africa: challenges and opportunities. Advances in agronomy, 94:55-133, 2007.

[14] F. Bazin, I. Hathie, J. Skinner, and J. Koundouno. Irrigation, food security and poverty Lessons from three large dams in West Africa. International Institute for Environment and Development and the International Union for Conservation of Nature, 2017.

[15] M. Bertoncin and A. Pase. Interpreting mega-development projects as territorial traps: the case of irrigation schemes on the shores of lake chad (borno state, nigeria). Geographica Helvetica, 72(2):243, 2017. 
[16] M. Bertoncin, A. Pase, D. Quatrida, and S. Turrini. At the junction between state, nature and capital: Irrigation mega-projects in sudan. Geoforum, 106:24-37, 2019.

[17] A. K. Biswas. Irrigation in africa. Land Use Policy, 3(4):269-285, 1986.

[18] E. Blanc and E. Strobl. Is small better? a comparison of the effect of large and small dams on cropland productivity in south africa. the world bank economic review, 28(3):545-576, 2014

[19] J. Burney, L. Woltering, M. Burke, R. Naylor, and D. Pasternak. Solar-powered drip irrigation enhances food security in the sudano-sahel. Proceedings of the National Academy of Sciences, 107(5):1848-1853, 2010.

[20] J. Carney. Converting the wetlands, engendering the environment: The intersection of gender with agrarian change in the gambia. Economic Geography, 69(4):329-348, 1993

[21] R. Chambers and J. R. Moris. Mwea: An irrigated rice settlement in Kenya. Number 83. Weltforum Verlag, 1973.

[22] C. de Bont. The continuous quest for control by african irrigation planners in the face of farmer-led irrigation development: The case of the lower moshi area, tanzania (1935-2017). Water Alternatives, 11(3):893-915, 2018.

[23] C. de Bont, H. C. Komakech, and G. J. Veldwisch. Neither modern nor traditional: Farmerled irrigation development in kilimanjaro region, tanzania. World Development, 116:15-27, 2019 .

[24] M. Duponchel, L. Chauvet, and P. Collier. What explains aid project success in post-conflict situations? The World Bank, 2010.

[25] B. Flyvbjerg. Policy and planning for large-infrastructure projects: problems, causes, cures. Environment and Planning B: planning and design, 34(4):578-597, 2007.

[26] B. Flyvbjerg. Survival of the unfittest: why the worst infrastructure gets builtand what we can do about it. Oxford review of economic policy, 25(3):344-367, 2009.

[27] B. Flyvbjerg. Policy and planning for large-infrastructure projects. Dialogues in Urban and Regional Planning, 4:223, 2010. 
[28] N. Gorelick, M. Hancher, M. Dixon, S. Ilyushchenko, D. Thau, and R. Moore. Google earth engine: Planetary-scale geospatial analysis for everyone. Remote sensing of Environment, 202:18-27, 2017.

[29] N. Green, B. K. Sovacool, and K. Hancock. Grand designs: Assessing the african energy security implications of the grand inga dam. African Studies Review, 58(1):133-158, 2015.

[30] M. A. Hanjra, T. Ferede, and D. G. Gutta. Reducing poverty in sub-saharan africa through investments in water and other priorities. Agricultural Water Management, 96(7):10621070,2009

[31] T. P. Higginbottom, E. Symeonakis, H. Meyer, and S. van der Linden. Mapping fractional woody cover in semi-arid savannahs using multi-seasonal composites from landsat data. ISPRS journal of photogrammetry and remote sensing, 139:88-102, 2018.

[32] ICID. Dakar declaration on irrigation: Building resilience and accelerate growth in sahel and west africa by boosting irrigated agriculture, 2013.

[33] L. A. Ika, A. Diallo, and D. Thuillier. Critical success factors for world bank projects: An empirical investigation. International journal of project management, 30(1):105-116, 2012.

[34] B. Jones. Desiccation and the west african colonies. The Geographical Journal, 91(5): 401-423, 1938.

[35] D. Kaufmann, A. Kraay, and M. Mastruzzi. The worldwide governance indicators: methodology and analytical issues. Hague Journal on the Rule of Law, 3(2):220-246, 2011.

[36] T. M. Li. Beyond the state and failed schemes. American anthropologist, 107(3):383-394, 2005.

[37] T. M. Li. The will to improve: Governmentality, development, and the practice of politics. Duke University Press, 2007.

[38] C. T. Lloyd, A. Sorichetta, and A. J. Tatem. High resolution global gridded data for use in population studies. Scientific data, 4(1):1-17, 2017.

[39] C. Mbara. Status of medium to large irrigation schemes in southern somalia. SWALIM technical reports, 2007. 
[40] D. J. Merrey and H. Sally. Another well-intentioned bad investment in irrigation: The millennium challenge corporation's' compact'with the republic of niger. Water Alternatives, 10(1), 2017.

[41] A. Mold. Will it all end in tears? infrastructure spending and african development in historical perspective. Journal of International Development, 24(2):237-254, 2012.

[42] J. R. Moris. Irrigation development in Africa: lessons of experience. Routledge, 1990.

[43] H. Müller, P. Rufin, P. Griffiths, A. J. B. Siqueira, and P. Hostert. Mining dense landsat time series for separating cropland and pasture in a heterogeneous brazilian savanna landscape. Remote Sensing of Environment, 156:490-499, 2015.

[44] M. Pal. Random forest classifier for remote sensing classification. International Journal of Remote Sensing, 26(1):217-222, 2005.

[45] P. Rufin, C. Levers, M. Baumann, J. Jägermeyr, T. Krueger, T. Kuemmerle, and P. Hostert. Global-scale patterns and determinants of cropping frequency in irrigation dam command areas. Global environmental change, 50:110-122, 2018.

[46] E. F. Schumacher. Small is beautiful: a study of ecomonics as if people mattered. Vintage, 1973.

[47] J. C. Scott. Seeing like a state: How certain schemes to improve the human condition have failed. Yale University Press, 1998.

[48] D. H. Thomas and W. M. Adams. Adapting to dams: agrarian change downstream of the tiga dam, northern nigeria. World Development, 27(6):919-935, 1999.

[49] G. J. Veldwisch, A. Bolding, and P. Wester. Sand in the engine: The travails of an irrigated rice scheme in bwanje valley, malawi. The Journal of Development Studies, 45(2):197-226, 2009 .

[50] R. Walsh and D. Lawler. Rainfall seasonality: description, spatial patterns and change through time. Weather, 36(7):201-208, 1981. 
[51] D. J. Weiss, A. Nelson, H. Gibson, W. Temperley, S. Peedell, A. Lieber, M. Hancher, E. Poyart, S. Belchior, N. Fullman, et al. A global map of travel time to cities to assess inequalities in accessibility in 2015. Nature, 553(7688):333-336, 2018.

[52] S. N. Wood. Fast stable restricted maximum likelihood and marginal likelihood estimation of semiparametric generalized linear models. Journal of the Royal Statistical Society: Series B (Statistical Methodology), 73(1):3-36, 2011.

[53] S. N. Wood. Generalized additive models: an introduction with R. Chapman and Hall/CRC, 2017.

[54] P. Woodhouse, G. J. Veldwisch, J.-P. Venot, D. Brockington, H. Komakech, and Â. Manjichi. African farmer-led irrigation development: re-framing agricultural policy and investment? The Journal of Peasant Studies, 44(1):213-233, 2017.

[55] World Bank. Chad: Appraisal of sategui-deressia irrigation project. World Bank Project Appraisal Reports, 145a-CD, 1974.

[56] World Bank. Lake chad polders project: Project performance audit report. World Bank, 592-C, 1987.

[57] World Commission on Dams. Dams and development: A new framework for decisionmaking: The report of the world commission on dams. Earthscan, 2000.

[58] C. Zarfl, A. E. Lumsdon, J. Berlekamp, L. Tydecks, and K. Tockner. A global boom in hydropower dam construction. Aquatic Sciences, 77(1):161-170, 2015. 
${ }_{509}$ Supplementary Figures 

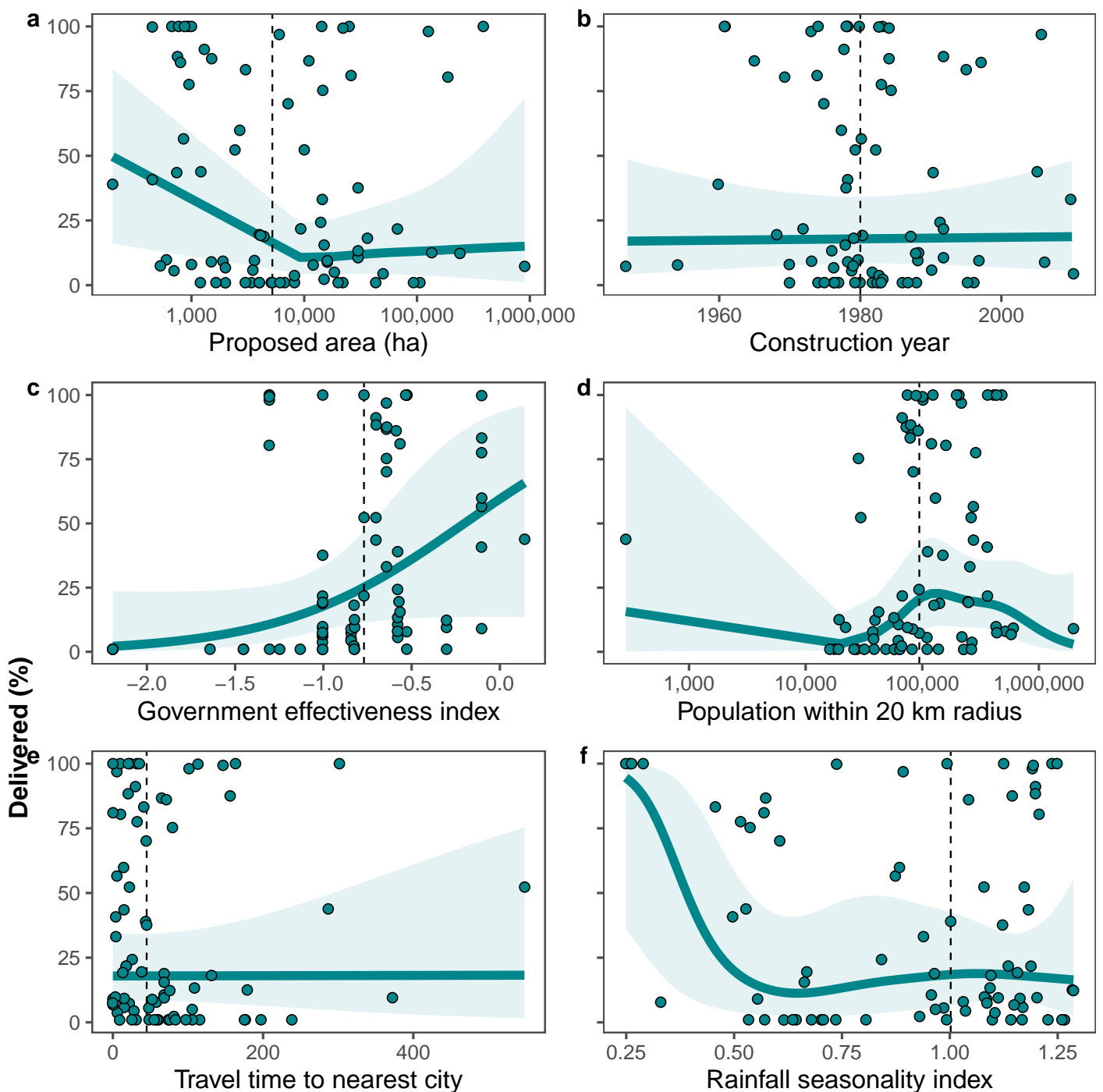

Population within $20 \mathrm{~km}$ radius
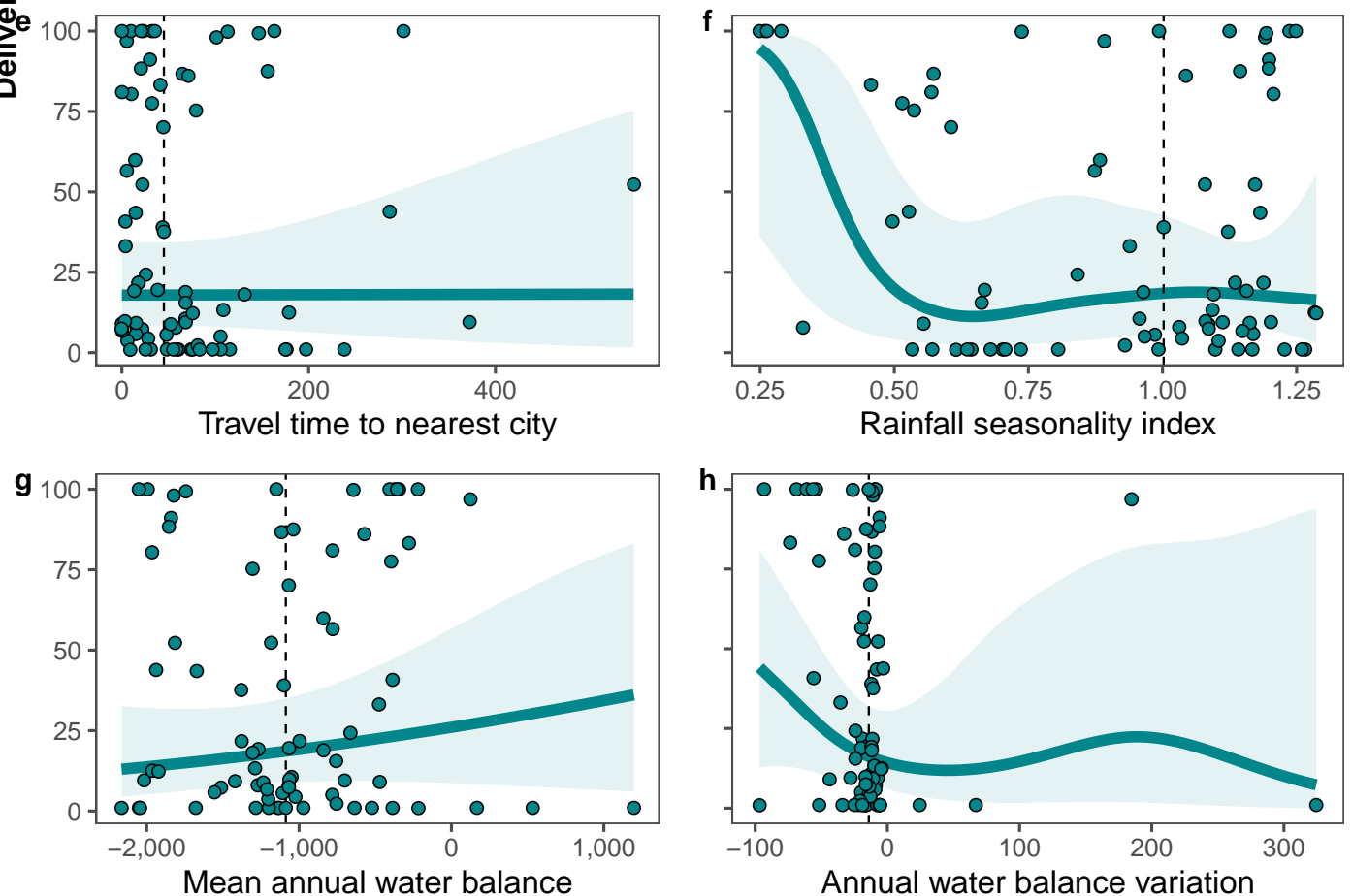

Figure 4: Relationships between delivered irrigated percentage and potential explanatory variables. Delivery percentage were capped at $100 \%$, solid lines are derived from quasibinomial GAMs (multiplied by 100), with shading showing $95 \%$ confidence intervals. Vertical dashed lines show the median value of the variable. 

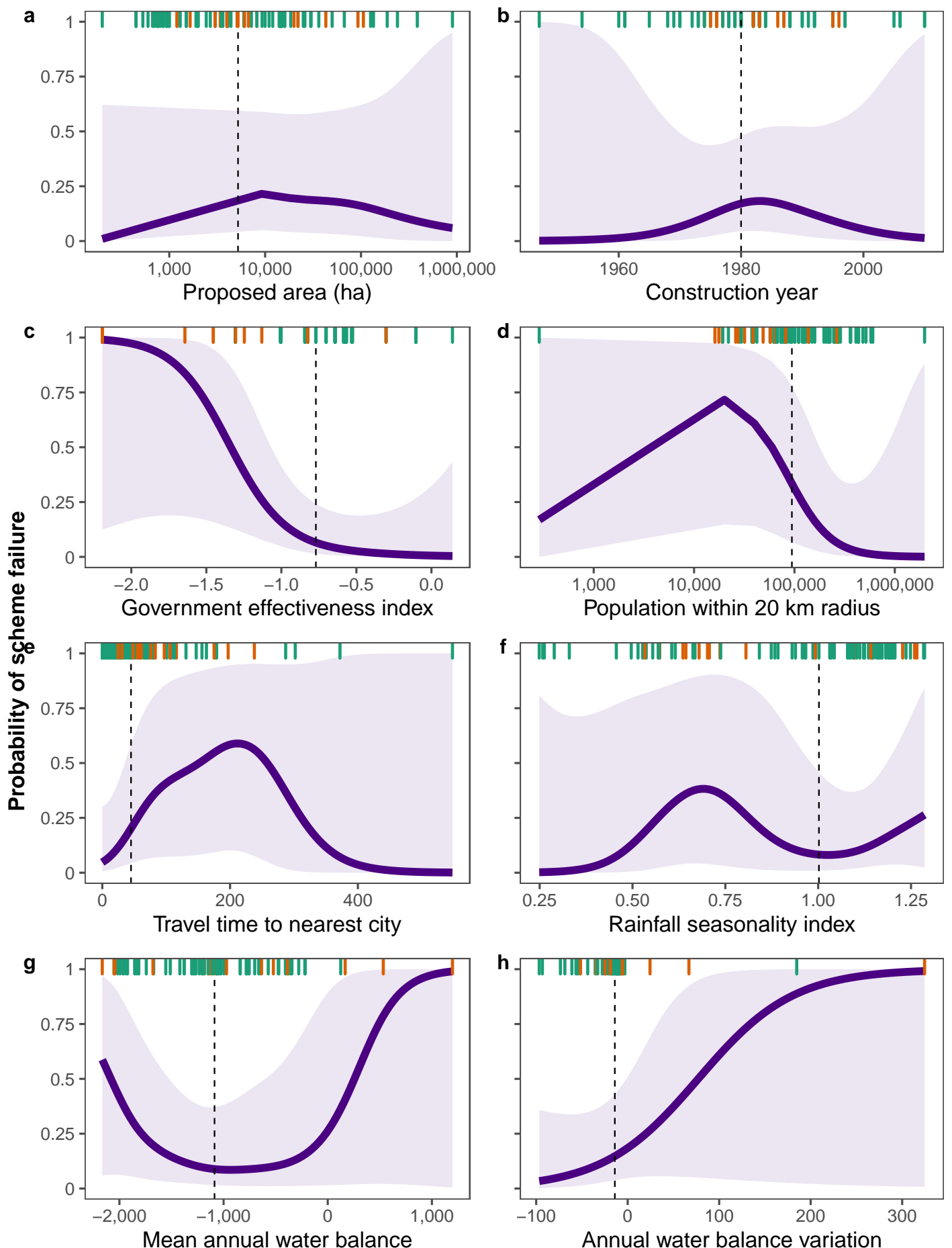
Scheme

Figure 5: Binomial models between delivered irrigation scheme status (failed/operational) and potential explanatory variables, solid lines derived from binomial GAMs with shading showing $95 \%$ confidence intervals. Rug plot lines show the distribution of scheme status (failure/operational). Vertical dashed lines show the median value of the variable. 